\title{
Editorial
}

\section{The political economy of Chinese health reform}

WILLIAM C. HSIAO*

Harvard School of Public Health, USA

Political economy studies of health policy offer more than simple economic or political studies. Politics can have a greater influence on health policy decisions and their implementation than either economic or health considerations. Politics constrain how much of an optimal economic or health programme can be adopted and implemented. At the same time, the economic interests of the stakeholders drive their political positions on any potential policy change. We need more political economy studies to understand how to craft and execute politically viable 'best' health policies. This editorial uses the decision choices facing China's health reform to illustrate the importance of political economic analysis and argues for more integrated political economy studies, particularly ones examining the roles of the health bureaucracy and the medical profession.

Political economy is a diverse field of study, embracing different theories and methods (Moe, 1997; Downs, 1965; Lindblom, 1959; Gamble, 1995). The role of experts in political economy has been studied extensively. In health policy, the role of the medical profession holds a special interest. The medical profession plays at least three exceptional political roles in health policy and implementation. First, health policy formulation and implementation require medical knowledge and expertise in delivering health care, both in the province of medical professionals. Second, physicians are the front-line troops whose daily medical practices determine how well a policy would perform. Hence, any major policy decision has to consider the grass-roots-doctors' views. Finally, the medical profession has an extraordinarily strong voice in health policy-making through easy access to every decision-maker because most households have one or more personal physicians. When the medical profession holds a common view on a health policy, it has a direct channel to policy-makers which can be used to further the profession's interests.

Many countries, including the United Kingdom, Germany, Chile, Colombia, and transition economies, have undertaken reform of their health systems. Several large countries such as Mexico, China, and India are in the midst of such reforms. We could advance our knowledge about policy choices, priority-setting,

*Correspondence to: Professor William C. Hsiao, Harvard School of Public Health, 124 Mt. Auburn St., Suite 410S, Cambridge, MA 02138, USA. Email: hsiao@hsph.harvard.edu 
decision-making, and implementation barriers through in-depth analysis of the political economy of these reforms. Such knowledge would provide insight on how to integrate political, economic, and health considerations to achieve desirable outcomes in reform efforts.

In this editorial I examine the political economy of China's health policymaking and argue that there has been a failure in the relationship between the top Chinese political leaders (the principal) and the health bureaucracy (the agent). The principal may want to the pursue public interest to maintain political power, which may be at odds with the economic and bureaucratic interests of the health bureaucrats. In China the health bureaucracy, hospital directors, and physicians are closely allied. The health bureaucracy derives its influence and power from the grass-roots support of hospitals and physicians. I term this tight alliance the medical axis-of-power. It can be powerful enough to pursue largely its own interests rather than those of the principal. Consequently, a major health reform may provide more benefits to the medical profession and health bureaucracy than to the population, as preliminary evidence of the UK reform seems to indicate (Maynard, 2007).

I begin with a brief explanation of the major problems confronting the health sector in China, followed by a review of its political structure. The third section analyzes the political economy of the two major alternative reforms being considered. I show the interplay and alignment of the politics, bureaucratic interest, and technocracy in making Chinese health policy. The conclusion comments on a few possible remedies and the lessons to be learnt from China's health reform.

\section{Major problems confronting the health sector}

The problems facing China's health system have been widely documented (Liu, 2004; Blumenthal and Hsiao, 2005; Watts, 2006). In essence, there are four current problems: under-funding and under-provision of public health and preventive services, the high cost of health care, unaffordable access to health care, and medical impoverishment.

Like other socialist countries, China historically has relied largely on public finance and public provision of health care. Its centrally planned economy created a surplus of low-quality hospital beds. To maintain full employment, the public facilities were over-staffed with modestly trained physicians, nurses, and ancillary staff. Even now, post-transition China has a surplus of low-quality hospital beds and poorly trained physicians, while lacking highly qualified specialists.

When China liberalized its economy in 1978, it transformed its centrally planned health care system to a market-driven system. It moved from one that provided prevention and affordable basic health care to all to one in which people cannot afford basic health care and many families are driven into poverty by 
medical expenses (Hesketh and Zhu, 1997a, 1997b; Lindelow and Wagstaff, 2005; Watts, 2006, 2007). What caused these dismal conditions?

Under its economic reform, China did not develop a comprehensive health insurance system for all. Households had to shoulder the lion's share of medical expenses when the cooperative medical system, which had formed the pillar of health security for 900 million peasant farmers, collapsed when collective farming shifted to private household farming and the commune welfare fund that supported the cooperative medical system disappeared. It left $90 \%$ of all peasants uninsured. In the cities, employment-based insurance shifted to individual medical savings accounts/catastrophic insurance, covering only about half of the urban population. As a result, out-of-pocket payments as a share of total health expenditure grew from $20 \%$ to almost $60 \%$ between 1978 and 2002 (Smith, Wong, and Zhao, 2005).

In its economic transition, the Chinese government experienced a drastic reduction in revenue. The government reduced funding for prevention and public health along with subsidies for public health facilities. Government subsidies made up a mere $10 \%$ of the facilities' total revenues by the early 1990 s, forcing health facilities to rely on patients' payments. Meanwhile, the government established an irrational pricing policy that set service prices below the actual costs, but allowed profit margins for drugs and new high-tech diagnostic services to make up the loss. For example, the officially sanctioned charge for an office visit is only $40-50 \%$ of the actual cost, while providers are allowed a $15 \%$ mark-up on drug prices. These perverse incentives, on top of a fee-forservice payment system, have led providers to over-prescribe drugs and tests and hospitals to introduce high-tech services and expensive imported drugs that yield higher profit margins (Liu and Mills, 1999). For example, $75 \%$ of patients suffering from a common cold are prescribed antibiotics as are $79 \%$ of hospital patients - over twice the international average of $30 \%$ (Zhou). This practice leads to high health care costs and drug resistance in patients.

\section{Political structure}

China has a highly centralized and authoritarian government, controlled by the Chinese Communist Party (CCP). The 22-member Politburo of the CCP sets policy, allocates budgets, and controls all administrative, legal, and executive appointments. Politburo members are elected for a five-year term by the Central Committee of the CCP. Decisions are made by consensus. At the apex of power is the nine-member Politburo standing committee, made up of the President, Chairman of the People's Congress, the Premier, and others. The President is the head of the state and chairs the CCP, and the Premier leads the executive branch of the government. Members of the National People's Congress are not elected by the people, but by CCP members. While the laws have to be enacted 
by the Congress, it has relatively little independent power. The Congress mostly passes laws to legitimize the decisions made by the Politburo (Lieberthal and Oksenberg, 1988). The courts are under the control of the CCP.

Nonetheless, political leaders need bureaucracy and institutionalized power to assist in formulating and executing policy. Many of the detailed activities in shaping and implementing policy take place in the bureaucracy.

The highest executive organ is the State Council led by the Premier and composed of close to 30 ministers plus heads of other administrative agencies (Central People's Government of the People's Republic of China). The Ministry of Health plays a critical role in shaping health policy and managing and coordinating various health activities.

\section{Political economy of China's health reform}

China is in the midst of deciding how to reform its health system, a decision that will influence the health care of 1.3 billion people for decades to come. The future health care cost burden for the aging Chinese population will also be determined by these decisions. What political economy underlies Chinese health policy and how may it determine winners and losers in health reform?

The Chinese Communist Party's legitimacy rests primarily on its performance in improving the population's welfare through economic growth and political stability. However, the party's standing among ordinary Chinese is undermined by several factors, including officials confiscating peasants' land without reasonable compensation, unaffordable access to health care and medical impoverishment, and rapidly increasing income disparity. These factors have stimulated unrest in both rural and urban areas. The number and size of protests has risen from 10,000 in 1994 to 87,000 in 2005 , involving close to 4 million people (Kahn, 2006).

Such social unrest represents a serious challenge to CCP power. President $\mathrm{Hu}$, Premier Wen, and other members of the Politburo have been working to address problems giving rise to the unrest. Reforming the financing and delivery of health care is one of their top priorities.

In March 2007, President $\mathrm{Hu}$ announced that the Chinese government is committed to substantially increasing its investment in health care. With a significant growth in tax revenue from a booming economy, China plans to inject an additional US \$25-38 billion of government funding - the equivalent of $1-1.5 \%$ of GDP - into health, with the goal of providing free or nearly free universal basic health care that consists of primary and secondary prevention, primary care in outpatient clinics, maternal and child health care, home health services for the disabled and elderly, emergency hospital services, and essential drugs. This represents a tripling of government spending on health. The magnitude of the increase rivals the new health investment of the UK under its 2000 NHS plan (UK Department of Health, 2000). 
The intention of China's Politburo is clear: it wishes to improve social and political stability by ensuring that basic health care is affordable and accessible for all and by reducing medical impoverishment. However, the goals of the Politburo may not necessarily be shared by the bureaucracy - the ministries. The goals of China's ministries seem to reflect widespread bureaucratic behaviour: to increase bureaucratic power through larger budgets, more personnel slots, and greater regulatory power (Downs, 1965). The pursuit of the public interest may be secondary. In short, there is a dissonance of goals between the principal (top political leaders) who wishes to address the social unrest by providing effective basic health services to everyone, and the agent (the bureaucracy) who wishes to pursue its own bureaucratic interest.

The Chinese situation is exacerbated by historical practice. Like the USA, China structured several ministries to represent certain special interest groups. For example, the Ministry of Labor and Social Security (MOLSS) mostly represents the interest of unions and labor organizations; the Ministry of Health $(\mathrm{MOH})$ mostly represents the interest of the public hospitals, physicians, and other health workers; and the Railway Ministry represents the interest of the national railways and their workers (Anonymous, 2003). This arrangement has created the medical axis-of-power where the $\mathrm{MOH}$ is allied with the interest of public hospitals and physicians in policy formulation and its implementation.

By injecting substantial government funding to provide universal basic health care, China has taken a giant step forward in addressing its problems of unaffordable access and medical impoverishment. But the initial funding decision is silent on how China will transform the new funding into effective and efficient services. It will require tackling inefficiencies and waste in the delivery system. How to accomplish this is the question under heated debate in China today, and two major alternatives are apparent. China can provide basic health care either through government facilities or through a regulated market. The ministries are engaged in an intense bureaucratic struggle over control of the new funds, personnel slots, and influence over the delivery of health care.

Under the government-provision approach, the new money would be given to the Ministry of Health $(\mathrm{MOH})$, who would then fund and manage public facilities. This is the traditional model that China has followed, relying on bureaucratic rules to allocate funds and manage public facilities and their staff. Providers do not have to compete for patients and therefore have little incentive to pay attention to or respond to patients' preferences, needs, and satisfaction. The $\mathrm{MOH}$ favors this approach because it would vastly increase its fiscal power, personnel slots, and appointment power.

The major problem is that the Chinese $\mathrm{MOH}$ has historically represented the interest of public hospitals, their physicians, and health workers, who are the political constituents and supporters of the MOH (Anonymous, 2003; Mao, 1965). As a result, the population's health and welfare often become a secondary concern. For example, as mentioned, public facilities exploit patients for 
profit by over-prescribing drugs and high-technology tests; the MOH has been unwilling to rein in such behaviour. If the $\mathrm{MOH}$ directs and manages public facilities providing basic health services, the new funds may go for higher compensation, more staffing, reduced workloads, and better working conditions for physicians and health workers, without producing more and higher quality services that meet the demands of the patients. When the funds are used inefficiently and are unable to meet patients' demand, the $\mathrm{MOH}$ could then reduce the scope of services as they determine what constitutes basic health services. Furthermore, available services may be limited as a result of waiting time, poor quality of service, and not allowing patients a choice of physicians. Dissatisfied patients would then seek services in the private sector, or pay under-thetable to jump queues. The UK has long found this model inefficient and has been trying to move away from it (Enthoven, 1991). Many European and middle-income countries have also moved away from the direct provision model.

The other alternative is the regulated-market approach. The government would separate its financing from direct provision roles. Instead, the government would act as an active and prudent purchaser, on behalf of the population, to select and contract with providers. Providers, be they public or private, would compete for contracts based on performance and cost, and receive a capitation payment for the populations served. The key advantage of this alternative is the potential beneficial effect on efficiency and quality of health services. Theoretically, the purchaser would do its best to pursue the patients' interests. When China established its urban social health insurance scheme, top political leaders recognized that the $\mathrm{MOH}$ would not be a suitable prudent purchaser, and this power and responsibility were given to the Ministry of Labor and Social Security (MOLSS). Unfortunately, experience to date shows that the MOLSS has not been an effective purchaser: it has not selectively contracted with providers on the basis of quality and performance, nor has it been able to contain the profit-seeking behavior of the providers or check cost inflation (Wang, 2000; Chen and Meng, 2002). Its primary concern has been to ensure that the insurance fund does not run a deficit and to avoid financial risks. People's access to health care, health improvement, and prevention of medical impoverishment are secondary concerns. When the fund runs deficits, benefit packages are reduced at the expense of the beneficiaries. MOLSS used its power to disburse insurance funds to gain private favours from hospitals and from pharmaceutical and medical-supply companies, such as to having these organizations sponsor overseas tours for the MOLSS staff.

Is it possible for China to establish a bureaucracy that may serve the public interest? One possibility involves organizing a new governmental purchaser composed of diverse bureaucratic interests to reduce the power of the medical axis-of-power - a commission composed of the ministries of Finance, Planning, Health, Labor, and Social Security. Thailand has adopted such an approach. The other alternative is to use private or community organizations as purchasers. 
Some countries such as Germany, The Netherlands, and Colombia have adopted this approach. But China does not have an established insurance industry or NGOs to perform this role

A regulated market is a strategy to improve the efficiency and quality of health service, but it requires an active and prudent purchaser who is motivated to advance patients' interest. Several purchasing organizations have been tried, including the GP fundholders, NGOs, and competing insurers. However, there are few rigorous evaluations of these models to yield generalizeable conclusions as to their effectiveness. We only have a few isolated cases of success.

\section{What can we learn from the political economy of the Chinese health reform?}

\section{Dissonance in the pursuits of the top political leaders and ministries: the agency problem}

There is a large body of literature on the dissonance of pursuits between the political leaders and the bureaucracy (Downs, 1965; Huang, 2002). The major issue involves how to change the behavior of the bureaucracy. China confronts the same challenge. Faced with the infusion of new, large government funding, it is unsurprising that the $\mathrm{MOH}$ would favour the government-provision approach and the MOLSS the regulated-market approach. But neither ministry is likely to pursue the fundamental goals of the Politburo. The history of $\mathrm{MOH}$ and MOLSS does not bode well for a major reformation of the Chinese health care delivery system unless the Politburo can hold them accountable for their performance.

The Politburo could hold the ministries accountable and partially remedy the dissonance by creating a new independent monitoring and evaluation agency to establish sound evaluation criteria and collect evidence assessing the performance of the responsible ministry. Otherwise, a large share of the new investment could be captured for the benefit of hospitals, physicians, and the pharmaceutical and medical equipment industries. In the past, the monitoring and evaluation roles have usually been filled by the ministry concerned, rendering these tools ineffective in assessing performance of that ministry.

China lacks the usual countervailing forces to balance the political power of the medical axis-of-power. In a democratic society, the free press, academics, NGOs, and grass-roots citizens' groups provide checks on such power.

\section{The medical axis-of-power}

While the Politburo has much greater power than the medical axis-of-power, the latter has what amounts to a veto power on health policy. Health policy reform and its implementation require the expertise and the day-to-day cooperation of physicians and hospital directors. Any reform policy adopted without 
their cooperation will likely fail during implementation. Just like military policy, it would be inconceivable that a nation can win a war without the military experts to help formulate the policy and the loyal support of the front line commanders and troops to fight the war.

Is there any remedy to this situation? One improvement seems possible. Again, an independent evaluation agency could be established to monitor and evaluate outcomes and hold the bureaucracy accountable. The outcomes would focus on what the public demands - improved access, health outcomes, efficiency, and quality. Governments have established independent financial audit agencies and I suggest this can be extended to audit performance. This new check and balance would apply whether there is direct provision by the $\mathrm{MOH}$ or a regulated market model using different purchasing organizations.

In conclusion, the political economy of Chinese health reform illustrates the dissonance of pursuits between the principal and agent. This is a classic problem that an elected legislature and president have with the bureaucracy. In health care, however, a medical axis-of-power may exist that could shift more power to the bureaucracy and the medical profession. In reforming its health system, China has to align the interests of the medical axis-of-power with its political goals. Otherwise, China will most likely see a significant portion of the new resources go to a bloated bureaucracy, and as higher income for the medical staff, more staffing, and reduced workloads. I argue that Chinese political leaders have to establish a new check and balance system, holding the bureaucracy accountable for improving people's access to basic health care, reducing waste, improving health status, and improving the efficiency and quality of health care. Such accountability requires an independent monitoring and evaluation agency.

\section{References}

Anonymous (2003), 'Zhang Wenkang discusses health reforms and the development of an important understanding', Jiankang Bao, 23 January. Online at: http://www.whjy. com.cn/html/hyxw.asp?id=80.

Blumenthal, D. and Hsiao, W. (2005), 'Privatization and its discontents - the evolving Chinese health care system', New England Journal of Medicine, 353(11): 1165-1170.

Central People's Government of the People's Republic of China, official website, www.gov.cn.

Chen, J. and Meng, G. (2002), 'The problems and policy recommendations to health insurance reform in urban China', Journal of Nanjing Medical University, 2(4): 317-320.

Downs, A. (1965), 'A theory of bureaucracy', The American Economic Review, 55(1/2): 439446.

Enthoven, A. (1991), 'Internal market reform of the British National Health Service', Health Affairs, 10(3): 60-70.

Gamble, A. (1995), 'The new political economy', Political Studies, 43(3): 516-530.

Hesketh, T. and Zhu, W.X. (1997a), 'Health in China: from Mao to market reform', British Medical Journal, 314(7093): 1543. 
Hesketh, T. and Zhu, W.X. (1997b), 'Health in China: the healthcare market', British Medical Journal, 314(7094): 1616.

Huang, Y. (2002), 'Managing Chinese bureaucrats: an institutional economics perspective', Political Studies, 50(1): 61-79.

Kahn, J. (2006), 'Pace and scope of protest in China accelerated in '05', New York Times, 20 January.

Lieberthal, K. and Oksenberg, M.C. (1988), Policy making in China, Princeton: Princeton University Press.

Lindblom, C. (1959), 'The science of “muddling through", Public Administration Review, 19(2): 79-88.

Lindelow, M. and Wagstaff, A. (April 2005), 'China's health sector - why reform is needed', prepared for China Rural Health AAA, Washington, DC: World Bank.

Liu, X. and Mills, A. (1999), 'Evaluating payment mechanisms: how can we measure unnecessary care?', Health Policy and Planning, 14(4): 409-413.

Liu, Y. (2004), 'China's public health-care system: facing the challenges', Bulletin of the World Health Organization, 82(7): 532-538.

Mao, Z. (25 June 1965) 'Guanyu yiliao weisheng gongzuo de zhongdian wenti', in Jianguo yilai Mao Zedong wengao, vol. 11 (1996), Beijing: Zhongyang wenxian chubanshe.

Maynard, A. (2007), 'Is doctors' self interest undermining the National Health Service?', British Medical Journal, 334(7587): 234.

Moe, T. (1997), 'The positive theory of public bureaucracy', in D. Mueller (ed.), Perspectives on Public Choice: A Handbook, Cambridge: Cambridge University Press.

Nelkin, D. (1975), 'The political impact of technical expertise', Social Studies of Science, 5(1): 35-54.

Smith, P., Wong, C. and Zhao, Y. (May 2005), 'Public expenditure and the role of government in the Chinese health sector', prepared for China Rural Health AAA, Washington, DC: World Bank.

UK Department of Health (2000), The NHS Plan, London: HMSO.

Wang, L. (2000), 'Shanghai's practice in reforming the medical insurance system', Chinese Journal of Hospital Administration, 16(5): 280-282.

Watts, J. (2006), 'China's rural health reforms tackle entrenched inequalities', Lancet, 367(9522): 1564-1565.

Watts, J. (2007), 'Protests in China over suspicions of a pay-or-die policy', Lancet, 369(9556): 93-94.

Williamson, J. (ed.) (1994), The Political Economy of Policy Reform, Washington, DC: Institute for International Economics.

Zhou, R. 'Responsible utilization of antibiotics should be a societal responsibility', Sanmenxia Central Hospital Paper No. 223. Online at: http://www.smxzxyy.com/Article_Print.asp? ArticleID $=213$. 